\title{
Inside a fund manager's mind
}

\author{
A life sciences fund manager reveals his decision-making process \\ for investing in biotech ventures.
}

\author{
Andrew Clark
}

There are two breeds of fund managers: the generalist and the specialist. The generalist covers a broad base of companies and looks at a whole range of industries. When faced with something as arcane as a biotechnology company, the generalist has little to go on but the current biotech story. If this is clear and understandable, and if sentiment in the market favors the sector, the generalist may make room in his or her portfolio for such a "blue sky" investment.

The specialist, by contrast, looks mainly at one sector, biotechnology in this case. This investor is not interested in a clear and simple story, for there is no such thing in biotechnology. Broadly speaking, the specialist is interested in competition, market size, intellectual property, management pedigree, and the scientific basis of the development. However, the end goal-to make a return for the investor-is the same for both the generalist and the specialist.

\section{Market background}

Before discussing the criteria I use to make investment decisions, it is important to understand the forces that have largely relegated biotechnology to the sidelines of the current bull market in equities. Though other contributors in this issue discuss many of these factors, there are a few that seem particularly germane.

The biggest factor in biotech's market difficulties is one of supply and demand-there are too many companies demanding too much money. I do not think there is anyone who would deny that a funding crisis looms over the sector, with many small public companies facing the prospect of running out of cash within the next two years. At the same time, venture capital groups, aided particularly in Europe by governmental agencies, are

Andrew Clark is a managing director at Reabourne, advisor to Reabourne Merlin Life Sciences Investment Trust, Alderman's House, Alderman's Walk, London EC2M 3XR, UK(aclark@reabourne.demon.co.uk).

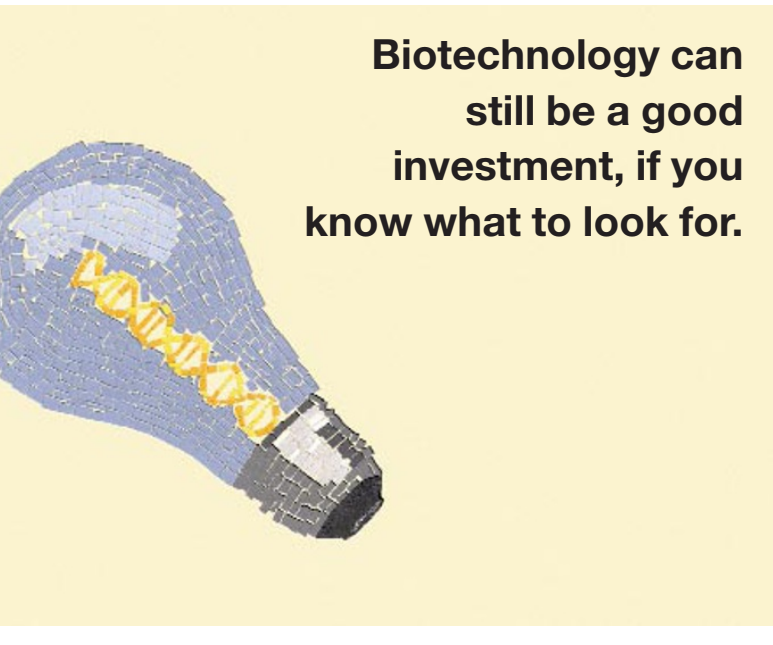

This is a make-or-break time for biotechnology. There is a huge pipeline of products in late-stage clinical trials or up for approval-over 200 at last count-and the many years of development must now be seen to pay off for the industry to regain investors' attention. The early signs are promising, but there is a definite "big is beautiful" theme to the market.

In 1998, biotechnology companies entering the year with a market capitalization on the order of $\$ 1$ billion enjoyed an appreciation of $80 \%$ on average over the year. Those companies

busily assembling scores of new biotechnology startups. Little consideration seems to have been given to how these fledglings will find the resources to survive, particularly given the travails of companies with several years head start.

Another key investing issue is that the science base of biotechnology is evolving rapidly, and biotechnology companies have yet to demonstrate that they can keep up with the pace of change in areas relevant to, but not core to their own focus. Over the past five years, for example, pharmaceutical companies have moved from a situation in which there was a paucity of targets to one in which there is a glut, thanks largely to deals such as the one between SmithKline Beecham (London) and Human Genome Sciences (Rockville, MD).

The result is that pharmaceutical companies are now interested in products first and foremost, and what was once a hot commodity-genomics companies-is now yesterday's news. With such rapidly shifting changes in technological emphasis, it is difficult for a fund manager to know if a company will be rendered obsolete by shifting scientific winds.

Finally, the explosion of Internet-related companies has negatively impacted the biotech sector. In any equity bull market, investors-including fund managers-will look to put a small portion of their portfolios into a "blue sky." In the early 1990s, the favored high-risk, high-reward sector was biotechnology; today it is the Internet. entering the year with a market capitalization of less than $\$ 200$ million saw a decline of $26 \%$ on average. Clearly, investing other people's money in biotechnology is not something done easily today.

\section{One investor's criteria}

That said, I still believe that biotechnology can be a good investment, if you know what to look for: First, the management team must be outstanding. It may sound like a cliché, but good management is still the single most important factor in the success or failure of an early-stage business. To illustrate this point, look at the UK biotechnology market and the common disastrous theme linking Biocompatibles (Farnham), British Biotech (Oxford), Celsis (Cambridge), Cortecs (London), Advanced Medical Solutions (Cheshire), and Scotia (Stirling). Management's excessive optimism to the investment community of the chances of success for a given product caused considerable damage to the sector, as well as souring perception of the individual company. This is not to say that management should not present their company in the best light to investors, but they must clearly strive for some balance.

The next item for examination is the company's business model, and this usually takes one of two forms: product oriented or platform technology. Business plans from product-oriented companies are straightforward, concentrating on the indication the company is pursuing, the competition, and a 
marketing strategy. Niche indications are fine, orphan ones even better if they are capable of supporting approval of a product that can provide a return commensurate with the costs borne in gaining approval.

Competition is usually the weak link in the chain; with over 2,000 biotechnology companies in the US, let alone Europe and the big pharmaceutical companies, competition is extremely hard to assess. This task becomes Herculean in areas of high patenting activity. It is practically impossible for anyone to predict who will eventually own what intellectual property in some areas. Indeed, the odds are high that there will be multiple overlapping claims keeping lawyers in employment for years as the ownership of genes and gene products is thrashed out.

As far as the marketing plan goes, we are most interested in how the company answers questions concerning how the product will be marketed, to whom, with what message, and by whom. Will the company be merely a "bag filler" for a major pharmaceutical partner, or does the company plan on detailing the product itself or with a smaller partner?

Platform companies raise different considerations. The first is what I call "royalty stacking." There are many useful technologies that can save a pharmaceutical company precious time in the drug development race. However, each technology often applies to only a small part of the whole development pipeline, so if the pharmaceutical firm is to pay a $2.5 \%$ royalty for the use of five different technologies, the big company will find itself in the position of having to spend $12.5 \%$ of the final product's sales when it reaches the market. Thus, a small firm's technology may go unadopted simply because there is no room left at the table.

This links to a second issue that I refer to as "salami slicing." The incremental advantage of each of these technology platforms becomes smaller as an ever-increasing number of technologies are spun out to form independent companies. Platform companies also face the previously mentioned threat of change in the underlying science, which may render it obsolete before it can realize a return on investment. The original Human Genome Project, for example, was scheduled to take decades; Celera (Rockville, MD) now talks about full genome sequencing in under three years. Obsolescence is the greatest threat to platform companies.

The next area for scrutiny is partnerships, often presented with great fanfare to investors. Clearly these are of great importance to the biotechnology industry, as they provide both cash and product endorsement. However, they should not be accepted as a good thing without close examination. Large companies enter such deals for many reasons: cheap research and development, competitor monitoring, perhaps even to slow the development of a potential competitor. There are many permutations to deals that must be considered carefully: how large is the upfront payment, what is the $\mathrm{R} \& \mathrm{D}$ commitment, what are the downstream royalties, what are the co-promotion rights, if any, and what are the obligations on each side. Many partnerships are undoubtedly of benefit to both sides, but there are many examples of biotechnology companies selling their crown jewels for too little.

Other considerations are more dependent upon the business plans of individual companies. Patents, as mentioned previously, are difficult and worth little in their own right unless they protect something valuable. Science for its own sake is not a proposition in which we can invest-if it has no commercial outlet, the research should be funded by grants, not equity markets. Finally, the industry is a global one, and investors should not rely on temporary discrepancies between markets. In other words, one should look for the best antibody technology, not the best Austrian antibody technology.

At a personal level, I look for two additional factors. First, the company's science or technology must be unique in some way. "Me too" approaches will not get my attention. Second, the company must be able to tell me why they will be able to accomplish what they are setting out to do when others cannot. If a company can put all this in a straightforward story, I am usually sold.

\section{Expectations}

Much is made of the volatility of the biotechnology sector and what investors should expect from their companies. I have my own list. What I expect to happen is that there will be product failures, slipping timelines, higher-than-expected burn rates, and unexpected decisions by partners. I am not saying that any of us enjoy these events, but we must understand the difficulties of new science and drug development. These are the issues with which we live.

What I do not want to see are negative surprises, good news that has been so thoroughly leaked it has no impact on the share price, hype, misrepresentation of data, exaggeration of market size, products left in the pipeline to "bulk it up," and finally, helicopters run for the benefit of CEOs of money-losing companies.

At the end of the day the shareholders, not the management, own the business, but true success comes when the two can work together. Biotechnology is truly the business opportunity of the 21 st century and there is nowhere else I would rather work. 